\title{
Voltammetric Adsorption Studies of Commercial Corrosion Inhibitors. A First Correlating Approach to the Corrosion Inhibition Efficiency
}

\author{
L.F. D'Elia, F. Torres, V. Báez \\ Petróleos de Venezuela (PDVSA)-Intevep, Gerencia General de Refinación e Industrialización, \\ Gerencia Técnica de Refinación, Apartado 76343, Caracas 1070-A, \\ República Bolivariana de Venezuela
}

Received 21 January 2009; accepted 13 November 2009

\begin{abstract}
Adsorption of film forming corrosion inhibitors on metallic surfaces led to a decrease in corrosion rates, since the adsorbed organic molecules behave as chemical and physical barriers for cathodic and anodic reactions. A novel and simple methodology to characterize commercial corrosion inhibitors is proposed. Fundamental studies of film forming corrosion inhibitors adsorption on platinum and its correlation with corrosion inhibition efficiencies of steel provide useful information for quality control of film forming inhibitors.
\end{abstract}

Keywords: corrosion inhibitors adsorption, corrosion inhibition, impedance spectroscopy, cycle voltammetry, adsorption-corrosion inhibition correlation.

\section{Introduction}

Oil exploitation and refining activities involve severe operation conditions (high pressure and temperature). These activities also deal with corrosive chemical species; for instance, $\mathrm{CO}_{2}, \mathrm{H}_{2} \mathrm{~S}$ and $\mathrm{Cl}^{-}$. Different methodologies can be used for material corrosion prevention: cathodic protection, inhibitors and others [1].

Based on the corrosion protection mechanism, inhibitors can be grouped in: (i) film forming inhibitors; (ii) hydrogen suppressor inhibitors; (iii) oxidative inhibitors; (iv) vapor phase inhibitors and (v) sequestrants [1]. Adsorption of film forming corrosion inhibitors on metallic surfaces led to a decrease in corrosion rates, since the adsorbed organic molecules behave as chemical and physical barriers for cathodic and anodic reactions. Imidazolines are considered the base

\footnotetext{
* Corresponding author. E-mail address: delialf@pdvsa.com
} 
components of ammine film forming inhibitors [2-6]; nevertheless, it has to be highlighted that there are other base component of film forming inhibitors; such as, alcohols, hydrocarbons and others. Imidazoline is adsorbed through nitrogen atoms; as a result, water and corrosive products do not reach the metallic surface [2-6].

The aim of this paper is to characterize the adsorption phenomenon of commercial corrosion inhibitors on platinum surfaces by cycle voltammetry (CV). Moreover, corrosion inhibition parameters of steel are evaluated by electrochemical impedance spectroscopy (EIS) and linear polarization resistance (LPR). Finally, it is proposed a correlation between adsorption of film forming inhibitors and corrosion inhibition efficiencies; therefore, a quality control protocol for film forming inhibitors can be established.

\section{Experimental}

Before experiments, cells and electrodes were washed with MONA 300 (organic solvent purchased from MONA Industrias de Venezuela) and deionized water.

\section{Voltammetric measurements}

Experiments were performed at $30{ }^{\circ} \mathrm{C}$ using a one compartment cell. A platinum disc $\left(1.25 \mathrm{~cm}^{2}\right)$ was used as working electrode, a platinum gauze as counter electrode and a saturated calomel electrode (SCE), separated by a Luggin capillary, as reference electrode. The working electrode was polished using alumina $(0.05 \mu \mathrm{m})$, degreased with acetone and thoroughly washed with deionized water.

Solutions are composed by corrosion inhibitors $\mathrm{A}, \mathrm{B}, \mathrm{C}, \mathrm{D}, \mathrm{E}$ and $\mathrm{F} \mathrm{x}$ ppm $+\mathrm{H}_{2} \mathrm{SO}_{4} 1 \mathrm{M}$ (corrosion inhibitors $\mathrm{A}, \mathrm{B}, \mathrm{C}, \mathrm{D}, \mathrm{E}$ and $\mathrm{F}$ are different in nature and trademarks). All evaluated inhibitors are usually employed for pipeline treatment in oil and gas operations. In general, they are based on mixtures of amine-hydrocarbon, amine-alcohol or alcohol-hydrocarbon. Before experiments, solutions were vigorously bubbled to ensure solution homogenization.

\section{Electrochemical impedance spectroscopy and linear polarization resistance measurements}

Experiments were performed at $30{ }^{\circ} \mathrm{C}$ using a one compartment cell. Three concentric steel 5LB-X52 electrodes were embedded in Plexiglas: working, counter and reference electrodes. Fig. 1 shows a frontal view of the three concentric electrodes design. The electrodes were polished using silicon carbide paper of different grades (240, 320, 400 and 600 grit), degreased with dehydrated alcohol and thoroughly washed with water.

Solutions are composed by corrosion inhibitor A x ppm+NACE solution $(\mathrm{NaCl}$ $5 \%+\mathrm{CH}_{3} \mathrm{COOH} 0.5 \%$ ) [7]. Corrosion inhibitor A was chosen, since it represents one of the most used inhibitors in oilfield and gas operation. Before experiments, sample solutions were vigorously bubbled to ensure solution homogenization. During experiments, the cell was kept under nitrogen atmosphere. 


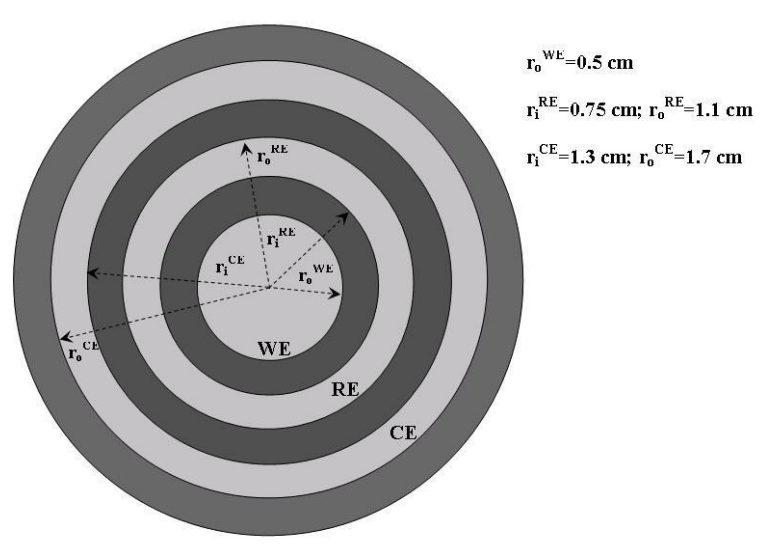

Figure 1. Frontal view of the three concentric electrodes design. WE: working electrode; RE: reference electrode; CE: counter electrode; $\mathrm{r}_{\mathrm{o}}$ : outer radius; and $\mathrm{r}_{\mathrm{i}}$ : inner radius.

\section{Results and discussions}

\section{Adsorption of commercial inhibitors on platinum}

Fig. 2 shows the cycle voltammograms (CVs) of platinum in a solution composed by corrosion inhibitor A $50 \mathrm{ppm}+\mathrm{H}_{2} \mathrm{SO}_{4} 1 \mathrm{M}$. Compare to the blank solution $\left(\mathrm{H}_{2} \mathrm{SO}_{4} 1 \mathrm{M}\right)$, hydrogen adsorption-desorption and oxide formationdissolution current peaks diminish in presence of corrosion inhibitors. In other words, these electrochemical reactions are suppressed by the corrosion inhibitor adsorption. This agrees with the behavior for platinum in dimethylsulphoxide (DMSO), pyridine and acetonitrile [8-10]; as well as, the adsorption on other surfaces [4-6]. The obtained voltammetric responses, while cycling the applied potential, change until they become stable. Therefore, values for the stabilize response are those that should be used for calculations.

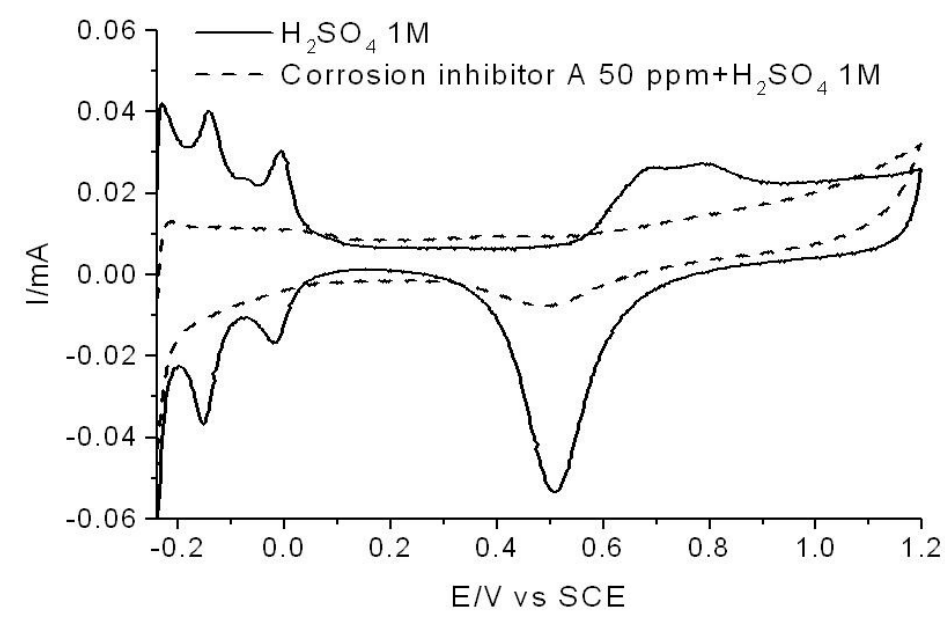

Figure 2. CVs of platinum in corrosion inhibitor A $50 \mathrm{ppm}+\mathrm{H}_{2} \mathrm{SO}_{4} 1 \mathrm{M} ; 100 \mathrm{mV} . \mathrm{s}^{-1}$.

Commercial film forming inhibitors may be also composed by other compounds such as, morpholine, isopropanole and kerosene. Fig. 3 shows that hydrogen adsorption-desorption peaks on platinum are not influenced by morpholine and 
isopropanole presence (compare to the blank solution). Same behavior has been obtained in our laboratories for platinum in kerosene containing solutions. Based on the facts stated above, corrosion inhibitor adsorption unequivocally relies on its base component. Fig. 4 shows that corrosion inhibitor adsorption is strongly influenced by inhibitor amounts; this effect still plays a key role even at low concentrations (5 ppm). It has to be mentioned that the same behavior was found for corrosion inhibitors B, C, D, E and F. Adsorption efficiencies of film forming corrosion inhibitor $\left(\mathrm{E}_{\mathrm{ads}}\right)$ were calculated according to the following equation:

$$
E_{a d}=\frac{Q_{\text {blank }}-Q_{\text {inh }}}{Q_{\text {blank }}} \times 100
$$

where $\mathrm{Q}_{\text {blank }}$ is the charge in absence of corrosion inhibitors and $\mathrm{Q}_{\text {inh }}$ is the charge in presence of corrosion inhibitors.

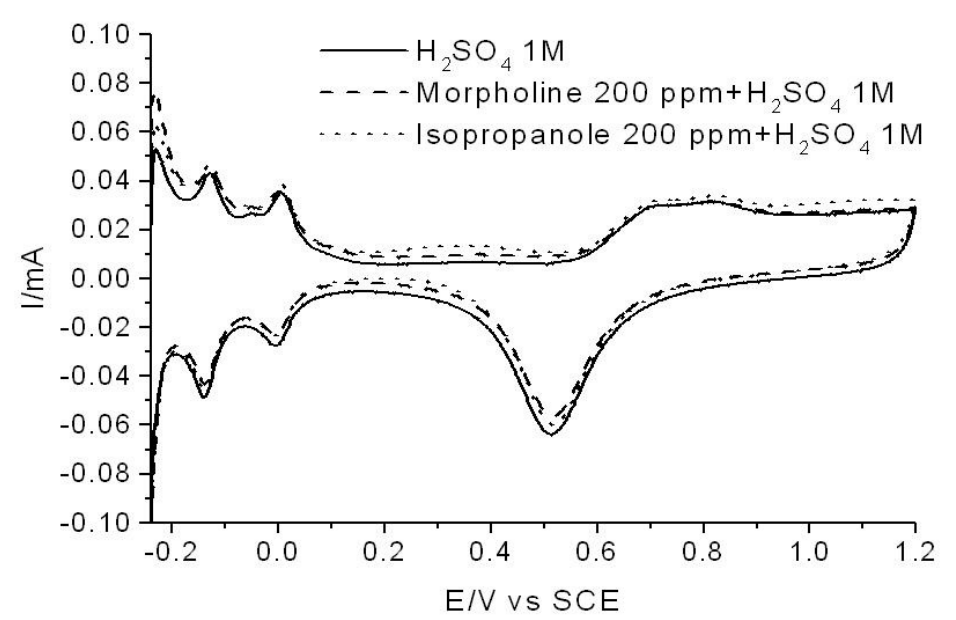

Figure 3. CVs of platinum in $\mathrm{H}_{2} \mathrm{SO}_{4} 1 \mathrm{M}$, morpholine $200 \mathrm{ppm}+\mathrm{H}_{2} \mathrm{SO}_{4} 1 \mathrm{M}$ and isopropanole $200 \mathrm{ppm}+\mathrm{H}_{2} \mathrm{SO}_{4} 1 \mathrm{M} ; 100 \mathrm{mV} . \mathrm{s}^{-1}$.

Figs. 5a and 5b show corrosion inhibitors adsorption efficiencies for different concentrations (calculated using charge data for two regions: hydrogen adsorption-desorption and oxide formation-dissolution). The highest adsorption efficiencies are obtained for corrosion inhibitors A, B and E. Film forming inhibitor $\mathrm{E}$ achieves high efficiencies at high concentrations. Corrosion inhibitors $\mathrm{C}, \mathrm{D}$ and $\mathrm{F}$ show the lowest adsorption efficiencies, thus interactions with the platinum surface may not be favored. It has to be highlighted that adsorption efficiencies can be either calculated using charge values for hydrogen adsorptiondesorption or oxide formation-dissolution regions. Similar behavior has been previously reported for DMSO and pyridine adsorption on platinum [8].

Using hydrogen adsorption-desorption charge data, adsorption efficiencies of film forming corrosion inhibitors were calculated at different concentrations. In addition, surface coverage $(\theta)$ values were also determined using the equation reported by Sobkowski and co-workers [8]: 


$$
\theta=\frac{Q_{H}^{i n h}-Q_{H}^{\text {blank }}}{Q_{H}^{i n h}-Q_{H}^{i n h-\min }}
$$

where $\mathrm{Q}_{\mathrm{H}}{ }^{\text {inh }}$ is the charge in presence of corrosion inhibitors, $\mathrm{Q}_{\mathrm{H}}{ }^{\text {blank }}$ is the charge in absence of corrosion inhibitors and $\mathrm{Q}_{\mathrm{H}}{ }^{\text {inh-min }}$ is the charge for the maximum surface coverage $(\theta=1)$. Similarly, Fig. $5 c$ shows that surface coverage increases with concentration until $\theta=1$.

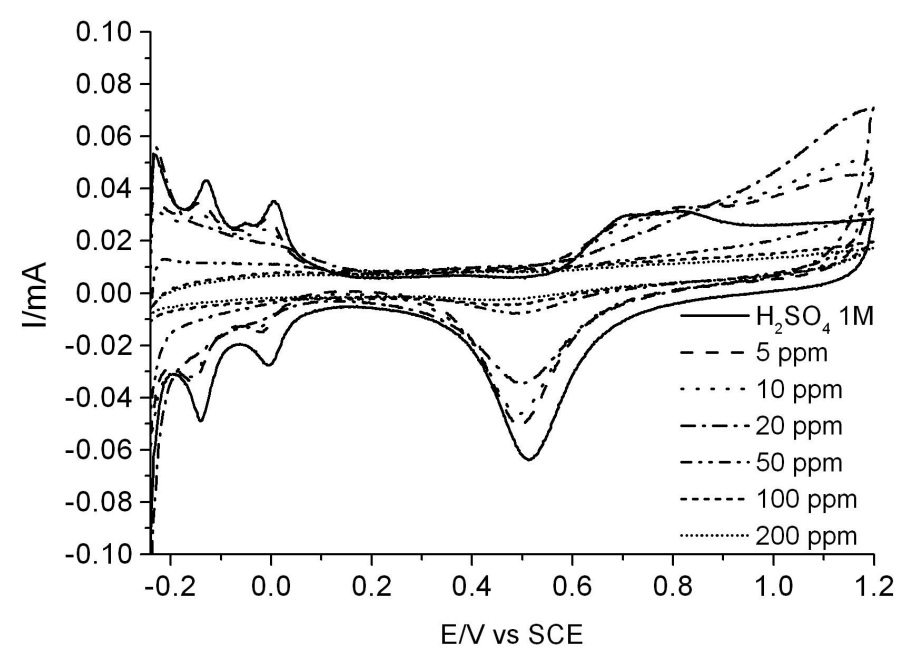

Figure 4. CVs of platinum in corrosion inhibitor $\mathrm{A} x \mathrm{ppm}+\mathrm{H}_{2} \mathrm{SO}_{4} 1 \mathrm{M}, 100 \mathrm{mV} \cdot \mathrm{s}^{-1}$.

a)

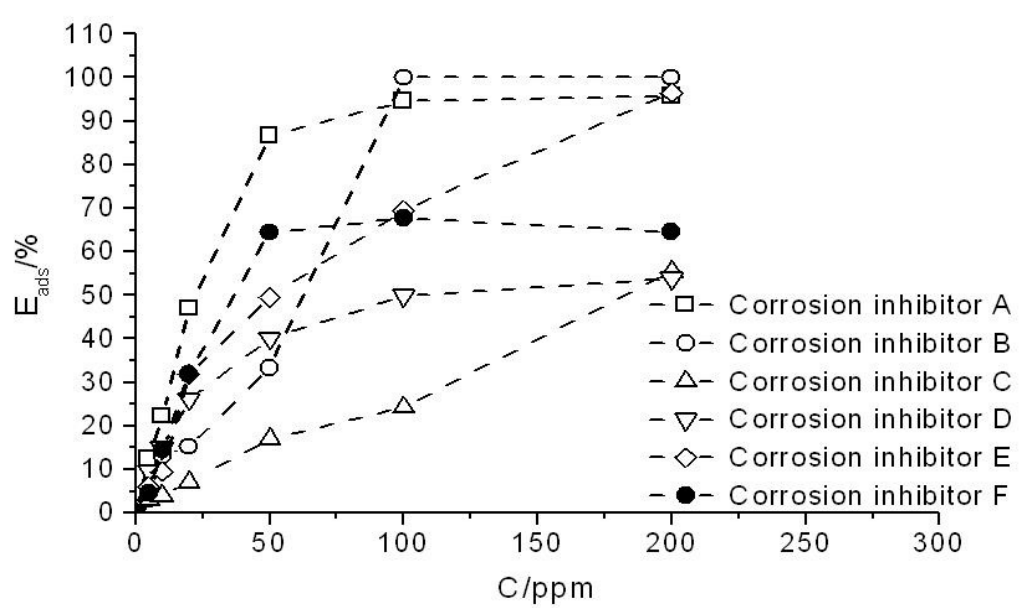

Figure 5. a) $E_{a d s}$ as a function of corrosion inhibitors concentration (calculated from hydrogen adsorption-desorption charge data).

Depending on the filmic corrosion inhibitors nature and concentrations, the adsorption features slightly differ from one to another. Unequivocally, corrosion inhibitor adsorption relies on its base corrosive protecting component. These fundamental aspects provide useful information for commercial film forming corrosion inhibitors characterization by means of their adsorption on platinum. 


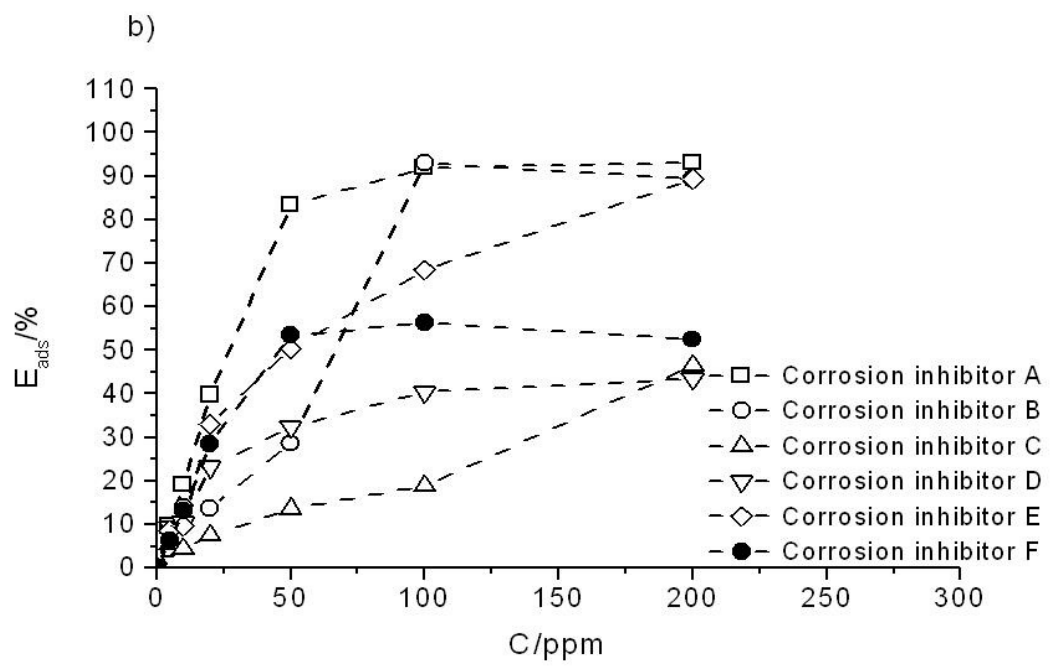

Figure 5. b) $E_{a d s}$ as a function of corrosion inhibitors concentration (calculated from oxide formation-dissolution charge data).

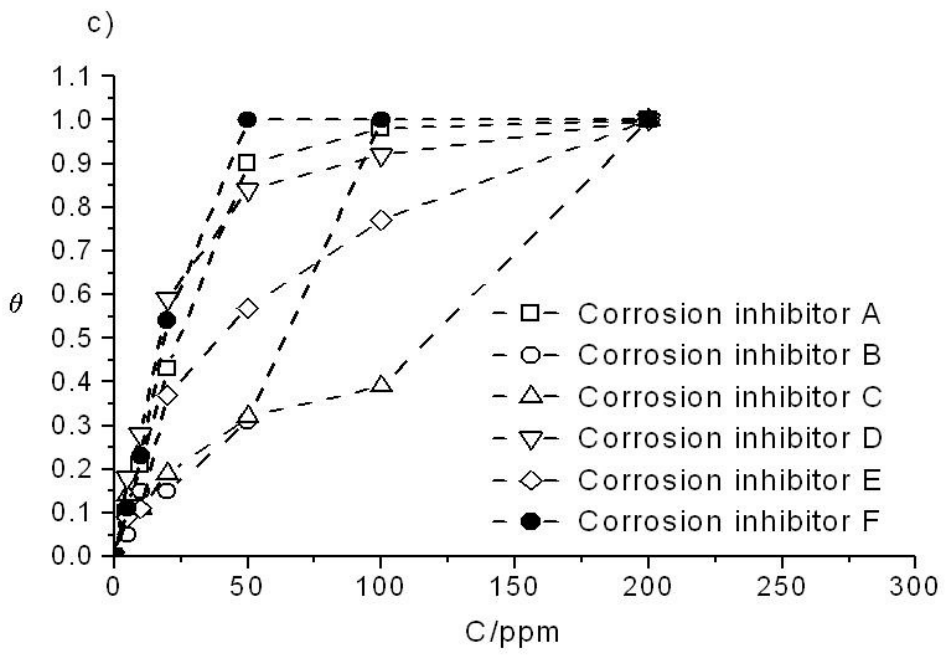

Figure 5. c) $\theta$ as a function of corrosion inhibitor concentration (calculated using hydrogen adsorption-desorption charge data).

\section{Corrosion inhibition features of commercial inhibitor A}

Corrosion efficiency was calculated using polarization resistance values obtained by EIS technique. LPR technique was used to verify that values obtained by LPR and EIS were self consistent. Fig. 6 shows the Nyquist diagrams collected from $5000 \mathrm{~Hz}$ to $0.05 \mathrm{~Hz}$ by applying $\pm 10 \mathrm{mV}$ vs. open circuit potential (OCP) for steel 5LB-X52 in a solution that contains corrosion inhibitor A $x$ ppm+NACE solution. 


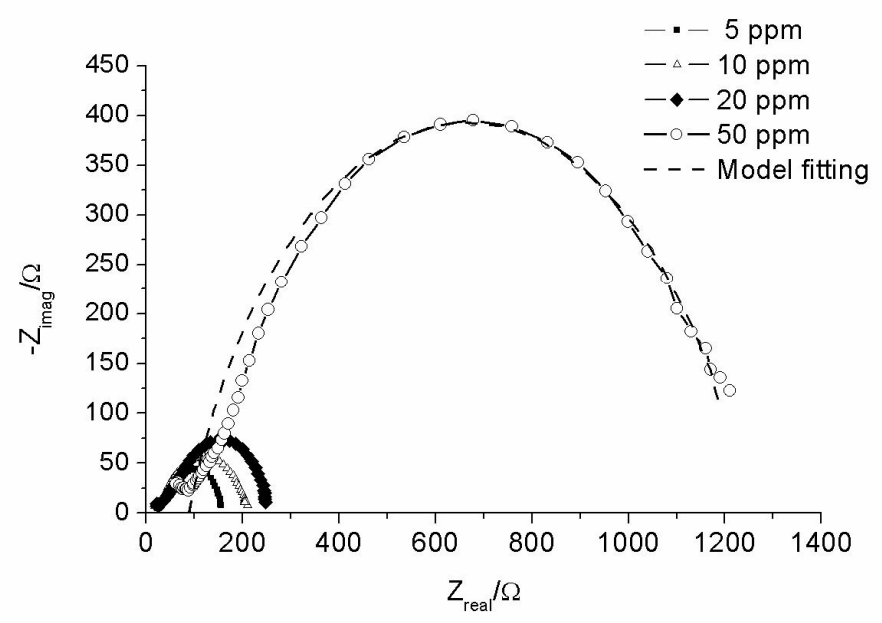

Figure 6. Nyquist diagrams obtained from $5000 \mathrm{~Hz}$ to $0.05 \mathrm{~Hz}$ of steel $5 \mathrm{LB}-\mathrm{X} 52$ in corrosion inhibitor A $x$ ppm+NACE solution.

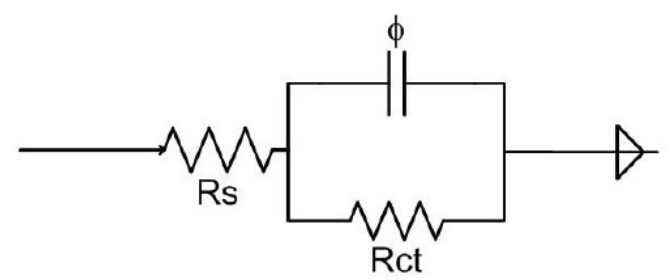

Figure 7. Equivalent circuit for steel 5LB-X52 in corrosion inhibitor A $x$ ppm+NACE solution.

Polarization resistance $\left(\mathrm{R}_{\mathrm{p}}\right)$ can be obtained from Nyquist diagrams by subtracting the $Z_{\text {real }}$ at high and low frequency intercepts when $-Z_{\text {imag }}=0$. In order to determine $R_{p}$ values, Nyquist diagrams are adjusted to theoretical curves that simulate equivalent electric circuit of electrochemical cells $[10,11]$. The most typical electric circuit is named as Randles circuit, which is composed by three elements: (i) solution resistance $\left(\mathrm{R}_{\mathrm{s}}\right)$; (ii) double layer capacitance $\left(\mathrm{C}_{\mathrm{dl}}\right)$ and (iii) charge transfer resistance or $R_{p}$.

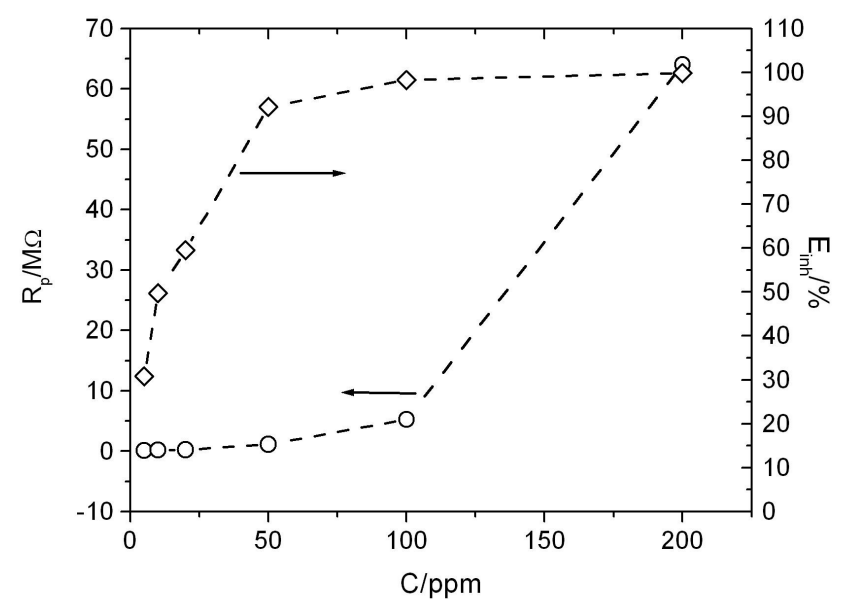

Figure 8. $R_{p}$ and $E_{i n h}$ as a function of corrosion inhibitor $A$ concentration. 
Experimental data did not fit the Nyquist diagrams predicted by Randles circuit. As a result, another electric circuit element (related to adsorption phenomena) was considered. The new equivalent circuit includes the so called constant phase element $(\phi)[10,11]$.

Fig. 6 shows experimental data fitting to the new equivalent electric circuit (dashed line). This is composed by a resistance element related to the solution resistance, a capacitance element related to the double layer, a constant phase element related to the corrosion inhibitor adsorption and a resistance component related to the corrosion charge transfer (Fig 7).

Fig. 8 clearly shows that $R_{p}$ values increase with the film forming inhibitor $A$ concentration. High corrosion inhibitor concentrations promote a thin film formation on the metallic surface; therefore, the corrosion inhibition efficiency $\left(E_{\text {inh }}\right)$ increases. $90 \%$ of $E_{\text {inh }}$ is achieved at low inhibitor concentration $(50 \mathrm{ppm})$, this high $\mathrm{E}_{\text {inh }}$ is a notable parameter to be considered when choosing a proper corrosion inhibitor dosing protocol.

\section{Correlation of the adsorption efficiency and corrosion inhibition efficiency for film forming inhibitors}

It was previously stated that corrosion inhibitors used for the experiments (A, B, $\mathrm{C}, \mathrm{D}, \mathrm{E}$ and F) are grouped as film forming inhibitors. For this reason, it is believed that a mathematical and physical correlation between corrosion inhibitor adsorption and its corrosion inhibition efficiency could be proposed.

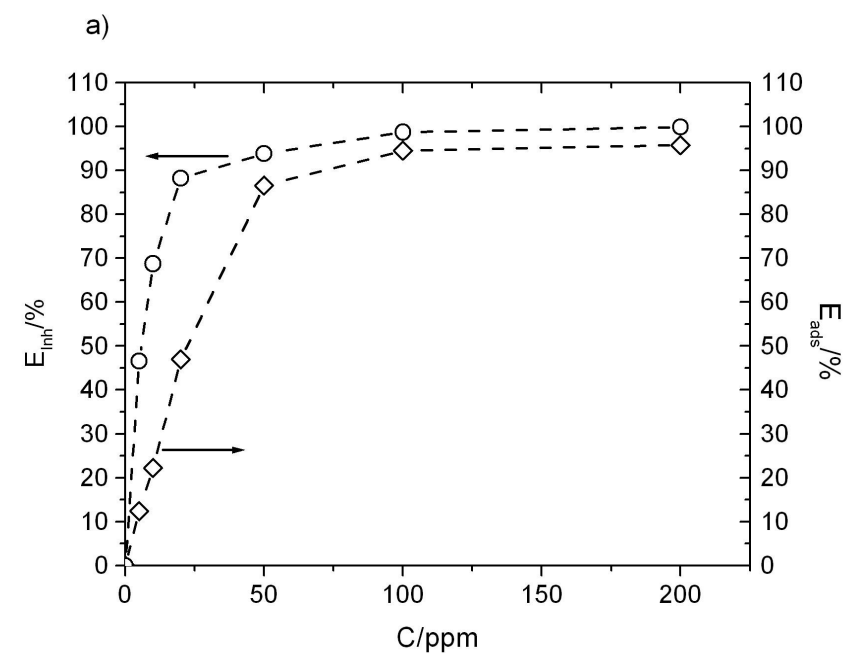

Figure 9. a) $E_{i n h}$ and $E_{a d s}$ as a function of corrosion inhibitor A concentration.

Fig. 9a shows that $\mathrm{E}_{\text {ads }}$ and $\mathrm{E}_{\text {inh }}$ follow the same tendency with corrosion inhibitor A concentrations. Moreover, Fig. $9 b$ shows that $E_{\text {inh }}$ increases as $E_{a d s}$ increases for corrosion inhibitor $\mathrm{A}$. This agrees with the fact that the corrosion inhibition mechanism is based on adsorption, thus corrosion protection is more efficient as corrosion inhibitor adsorption is favored. $\mathrm{E}_{\mathrm{inh}}$ and $\mathrm{E}_{\mathrm{ads}}$ data could be correlated through a Neperian logarithm function, according to the equation:

$$
E_{\text {inh }}=15.3+19.3 \operatorname{Ln} E_{\text {ads }}
$$


Further work has to be performed in order to understand the physicochemical meanings of the mathematical correlation. The correlation fitting parameters may be related to surface interaction strengths and electrolytic medium elements, since they are the main differences between the evaluated systems: corrosion inhibitors adsorption on Pt surface in acid solution vs. corrosion inhibition of steel in NACE solution. In order to confirm that the same relationship can be proposed for corrosion inhibitors B, C, D, E and F similar work has to be carried out.

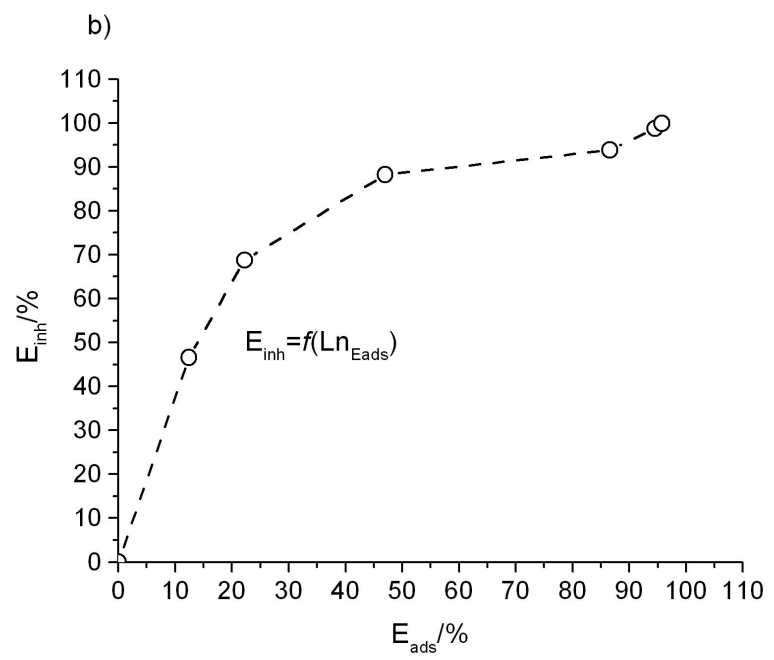

Figure 9. b) $E_{i n h}$ as a function of $E_{a d s}$.

\section{Conclusions}

Adsorption of commercial film forming inhibitors on platinum is a novel methodology to characterize inhibitor base components, since its chemical composition is completely unknown. The advantage of the present application is reinforced by the fact that only base corrosion inhibitor components are adsorbed on the surface.

Corrosion inhibitor adsorption depends on corrosion inhibitor concentration, since the adsorption increases with concentration until a steady value. Corrosion inhibitor A achieves acceptable corrosion inhibition efficiencies (>90\%) at 50 ppm. Corrosion controlling and preventing methodologies cost is proportionally affected by the added corrosion inhibitor dose. As a result, this is a notable parameter to be considered, when defining a dosing protocol.

The high inhibition efficiency at $50 \mathrm{ppm}$ supports the fact predicted by the corrosion inhibitor adsorption efficiencies obtained for inhibitor A. Corrosion inhibitor adsorption efficiencies do not show notable changes at inhibitor concentrations higher than $50 \mathrm{ppm}$. It has been shown that there could be a Neperian logarithm relationship between corrosion inhibition efficiency of steel in NACE solution and corrosion inhibitors adsorption efficiency on Pt surface in acid solution. The found correlation could be related to some physical parameters; for instance, surface interaction strengths and electrolytic medium elements. 
$\mathrm{E}_{\mathrm{inh}}-\mathrm{E}_{\mathrm{ads}}$ correlations provide useful information to characterize the inhibition efficiency of a certain inhibitor by means of a simple adsorption test on platinum in acidic media.

\section{Acknowledgements}

Authors would like to thank PDVSA-Intevep (Research and Development Centre of Petróleos de Venezuela, PDVSA) for the permission of publishing this work.

\section{References}

1. P.R. Roberger, Handbook of Corrosion Engineering, McGraw-Hill, New York, 2000.

2. Z. Foroulis, Molecular designing of organic corrosion inhibitors, Naval Research Office, New York, 1996.

3. A. Edwards, C. Oborne, D. Webster, M. Klenerman, Corros. Sci. 36 (1994) 315.

4. $\quad$ Lj. Vračar, D. Dražić, Corros. Sci. 44 (2002) 1669.

5. P. Kern, D. Landolt, J. Electrochem. Soc. 148 (2001) B228.

6. E.A. Noor, A.H. Al-Moubaraki, Materials Chemistry and Physics 110 (2008) 145.

7. NACE International, NACE Standard Test Method TM0177-2005 Item No. 21212.

8. J. Sobkowski, M. Szklarczyk, Electrochim. Acta 25 (1980) 383.

9. J. Sobkowski, A. Wieckowski, J. Electroanal. Chem. 34 (1972) 185.

10. A.V. Rudnev, E.B. Molodkina, A.I. Danilov, Y.M. Polukarov, A. Berna, J.M. Feliu, Electrochim. Acta 54 (2009) 3692.

11. Southampton Electrochemistry Group, Instrumental Methods in Electrochemistry, Ellis Horwood, 1985.

12. J.R. Macdonald and W.B. Johnson, In: E. Barsoukov, J.R. Macdonald, (eds) Impedance Spectroscopy Theory, Experiment and Applications, 2nd edn. John Wiley \& Sons, Inc., New Jersey, 2005. 